
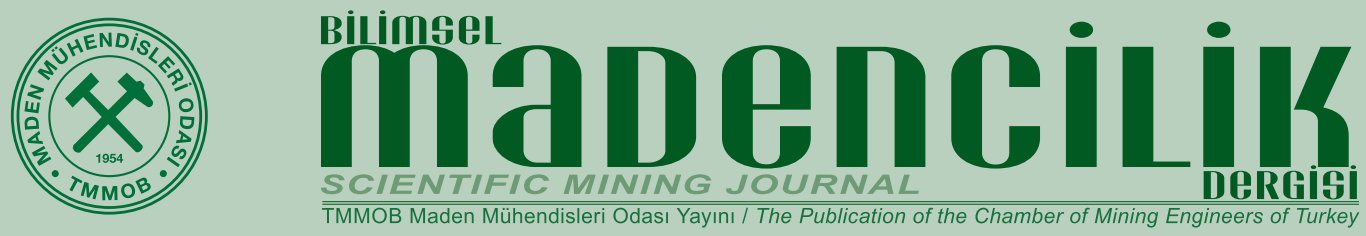

Orijinal Araştırma / Original Research

\title{
KARBONAT KÖKENLI BAZI DOĞAL TAŞLARIN YÜZEY ÖZELLIKLERINE BAĞLI OLARAK GÜNEŞ IŞIĞINI YANSITMA INDEKS DEĞERLERINDEKI DEĞIŞIMIN INCELENMESI
}

\section{INVESTIGATION OF THE SOLAR REFLECTION INDEX VALUES CHANGES OF SOME CARBONATE BASED NATURAL STONES DEPEND ON THE SURFACE PROPERTIES}

\author{
Raşit Altındağ ${ }^{a, *}$, İbrahim Uğur ${ }^{a, * *}$, Nazmi Şengün ${ }^{a, * * *}$, Deniz Akbaya, ${ }^{a, * * * *}$, Servet Demirdağ ${ }^{a, * * * * *}$, \\ Ahmet Coşkun ${ }^{\mathrm{b} * * * * * *}$, Murat Sert $\mathrm{c}^{\mathrm{c}, * * * * * * *}$, \\ a Süleyman Demirel Üniversitesi, Maden Mühendisliği Bölümü, İsparta, TÜRKIYE \\ b Süleyman Demirel Üniversitesi, Makine Mühendisliği Bölümü, Isparta, TÜRKIYE \\ ${ }^{c}$ Afyon Kocatepe Üniversitesi, Maden Mühendisliği Bölümü, Afyonkarahisar, TÜRKIYE
}

$\begin{array}{lll}\text { Geliş Tarihi / Received } & : & 22 \text { Mayıs / May } 2018 \\ \text { Kabul Tarihi / Accepted } & : & 22 \text { Ağustos / August } 2018\end{array}$

\section{Anahtar Sözcükler:}

Doğal taş,

Renk,

Doku,

Güneş ışığını yansıtma indeksi,

Yüzey işleme,

Enerji verimliliği,

Fiziksel bozundurma.

Keywords:

Natural stone,

Color,

Texture,

Solar reflectance index,

Surface treatment,

Energy efficiency,

Physical weathering.

\section{öz}

Günümüzde farklı renk ve doku özelliklerine sahip doğal taşlar, gerek dış cephe ve yer, gerekse iç mekân kaplamalarında, çeşitli kalınlıklarda ve yüzeyleri farklı şekillerde işlenmiş (cilalı, honlu ve kumlamalı) olarak yaygın şekilde kullanım alanı bulmaktadır. Özellikle dış cephelerde, güneş ışığının ortama yansıtılması ve soğurulması, mimari yapının iklimsel koșulları (mevsimsel sıcaklık ortalaması, güneşli gün sayısı, ortalama en yüksek sıcaklık, ortalama güneşlenme süresi vb.) baz alındığında, enerji verimliliği ve ısısal konfor açısından oldukça önemli sonuçlar doğurabilmektedir.

Bu çalışma kapsamında, gerek yurt içi ve gerekse yurt dışında yüksek ticari öneme sahip farklı renk, doku ve yüzey (cilalı, honlu ve kumlamalı) özelliklerine sahip 5 farklı karbonat kökenli (kireçtaşı, rekristalize mermer, traverten) doğal taş türüne ait numuneler kullanılmıştır. Kuru ve doygun durumda güneş ışığı yansıma ve ısıl yayılım değerleri ölçülerek, güneş ışığını yansıtma indeks değerleri hesaplanmıştır. Kuru ve doygun durum için hesaplanan güneş ışı̆ıını yansıtma indeks değerinin, yüzey özelliklerindéki değişime bağlı olarak önemli derecede değişimler gösterdiği gözlenmiştir.

\section{ABSTRACT}

Currently, natural stones having different colour and texture properties are widely used as both exterior and interior surface and floor coverings at various thicknesses and in different surface processed shapes (polished, honed and sanded). Especially on the outer facades, the reflection and absorption of the sunlight to the environment can have considerable consequences in terms of energy efficiency and thermal comfort based on the climatic conditions of the architectural structure (seasonal temperature average, number of sunny days, average maximum temperature, average sunshine duration etc.).

Within the scope of this study, samples of 5 different carbonate based (limestone, re-crystallized marble, travertine) natural stone types with different colour, texture and surface properties (polished, honed and sanded) with high commercial importance were used. In dry and saturated conditions, sunlight reflectance and heat emission values were measured and solar reflection index values were calculated. It has been observed that the solar reflection index values, calculated for dry and saturated conditions varies considerably depending on the changes in surface properties.y.

\footnotetext{
Sorumlu yazar: rasitaltindağ@sdu.edu.tr * https://orcid.org/https://orcid.org/0000-0002-5397-7312

** ribrahimugur@sdu.edu.tr * https://orcid.org/https://orcid.org/0000-0002-1872-9516

*** nazmisengun@sdu.edu.tr * https://orcid.org/https://orcid.org/0000-0003-0407-7198

**** denizakbay@sdu.edu.tr * https://orcid.org/... https://orcid.org/0000-0002-7794-5278

***** servetdemirdag@sdu.edu.tr * https://orcid.org/... https://orcid.org/0000-0001-7838-388X

****** ahmetcoskun@sdu.edu.tr * https://orcid.org/0000-0002-3351-4898

******* msert@aku.edu.tr * https://orcid.org/ https://orcid.org/0000-0001-6595-1681

Bu bildiri 2017 yılında düzenlenen Türkiye 9. Uluslararası Mermer ve Doğaltaş Kongresi ve Sergisi Bildiriler Kitabı'nda yayınlanmıştır. /

This paper was published in the 9th International Marble and Natural Stones Congress of Turkey held in 2017.

Bu makalenin tüm yayın hakları TMMOB Maden Mühendisleri Odası'na aittir @ 2018 / Copyright ( 2018 Published by UCTEA Chamber of Mining Engineers of Turkey. All rights reserved.
} 


\section{GíRiş}

Hızla gelişen teknolojiye paralel olarak, enerji verimliliği, birçok sektör ve alanda karşımıza çıkmakta ve enerji maliyetleri her geçen gün artış göstermektedir. Genellikle binalarda dış cephe kaplama malzemesi olarak kullanılan doğal taş plakalarının estetik görünümünün yanında enerji verimliliğine katkısı da bulunabilmektedir (Shi ve Zhang, 2011).

Güneş ışığını yansıtma indeks (solar reflection index, SRI) değeri binalarda kullanılan kaplama malzemelerinin enerji verimliliğinin değerlendirilmesinde önemli bir parametre olarak kullanılmaktadır. Farklı renk, doku ve yüzey özellikleri güneş ışığını yansıtma ve soğurma karakteristiklerine bağlı olarak inşa edilen bir yapının çevresinde oluşturduğu en önemli etkilerden birisi ortam sıcaklığının arttığı bölgelerde ısı adası oluşumudur (Kültür ve Türkeri, 2012). Isı adaları yüzeylerin neredeyse tamamının sentetik yapıda olduğu şehirsel yaşam alanlarında daha yaygın olarak görülmektedir. Özellikle güneş kaynaklı ışımayı yansıtma özelliği oldukça düşük düzeyde olan çatı ve beton yüzeyler güneşin neden olduğu ısıyı büyük oranda yutarak ısı adalarının oluşumuna katkıda bulunurlar. Yapı tarafından yutulan ısı konveksiyon yoluyla tekrar ortam havasına geri döndüğünde, artan sıcaklığa bağlı olarak havanın kalitesi, doğal kaynaklar ve ekosistem üzerinde olumsuz bir etki oluşturabilmektedir.

Literatür incelendiğinde bu alanda farklı çalışmaların olduğu görülmektedir. Levinson vd., (2010), SRI değerlerinin kaplama yüzeyinin yönü, güneşin pozisyonu ve atmosferik şartlarına bağlı olduğunu belirtmektedirler. Ma vd., (2001), güneş ışığından daha fazla yararlanabilmek amacıyla renk değiştiren kaplamalar üzerinde güneş ışığı yansıtma ölçümleri yapmışlar ve kırmızı ve mor renklerin arasındaki kaplamaların beyaz renge göre daha çok güneş ışığını absorbe ettiğini belirtmişlerdir. Sleiman vd., (2011) ABD'nin sıcak bölgelerinde binaların çatılarının yüksek güneş ışığını yansıtıcı özellikli malzemelerle kaplanmasıyla yaşam alanlarındaki iklimlendirme talebinin azalacağı sonucuna varmışlar, böylelikle şehirlerin ıSı adalarında da kayda değer bir azalış olacağını ve bunun sonucu olarak küresel ısınmanın azalacağını belirtmişlerdir. Boriboonsomsin ve Reza (2007), çalışmalarında bölgelerdeki ısı adalarının etkilerinin azaltılması için yüksek güneş ışığını yansıtma değerlerine sahip kaldııım- ların tasarlanması gerektiğini tespit etmişlerdir. Yüksek yansıtma değerinin elde edilebilmesi için alternatif olarak beyazlığın arttırılması gerektiğini savunmuşlardır. Berdahl ve Bretz (1997), çatı kaplamalarının güneş ışığını yansıtma değerleri kullanılan malzeme çeşitliliğine, yüzey pürüzlülüğü ve yabancı madde miktarına bağlı olarak değişimini incelemişler ve güneş ışığını yansıtma değerleri ile yüzey sıcaklıkları arasında kuvvetli bir korelasyon olduğunu ifade etmişlerdir. Alchapar vd., (2013), tarafından yapılan çalışmada, kentsel sıcaklıkların (ısı adaları) azaltılması amacıyla sık kullanılan yaya kaldırım kompozisyonları şekil ve renklerine bağlı olarak SRI değerlerini ve ısıl davranışlarını ölçerek, zamana bağlı kirlenmenin SRI ve ısıl davranışlarına etkilerini incelemişlerdir.

Bu çalışmada, farklı renk, doku ve yüzey (cilalı, honlu ve kumlamalı) özelliklerine sahip 5 farklı karbonat kökenli (kireçtaşı, re-kristalize mermer, traverten) doğal taş türüne ait numunelerin, kuru ve doygun durumda güneş ışığı yansıma ve ısıl yayılım değerleri ölçülerek, güneş ışığını yansıtma indeks değerleri hesaplanmıştır. Kuru ve doygun durum için hesaplanan güneş ışığını yansıtma indeks değerinin, yüzey özelliklerine bağlı olarak değişimi incelenmiştir.

\section{GÜNEŞ IŞIĞINI YANSITMA INNDEKS DEĞERI (SRI)}

SRI değeri, bir malzemenin güneşten yayılan enerjiyi yansıtma kabiliyeti olarak tanımlanmaktadır. Isıl yayılım ise bir yapının ısıyı serbest bırakma kabiliyeti olarak tanımlanabilmektedir. Güneş ışığı yansıtma değeri ve ısıl yayılım değeri 0 ile 1 arasında değişmektedir. Isıl yayılım değerinin büyüklüğü emilen enerjinin daha çok serbest kaldığını ifade etmektedir. Güneş ışığı yansıma indeks değeri açık yüzeyler için 100'e yakın, koyu yüzeyler için ise 0'a yakın değerler almaktadır.

Malzemenin SRI değerinin artması ortamda ISI adası oluşumunun azalmasına neden olmaktadır. Yüksek SRI değerleri göreceli olarak daha serin malzemeleri temsil etmektedir. Numunelerin Güneş Işığını Yansıtma İndeks (Solar Reflection Index, SRI) değerlerinin belirlenmesi için Güneş Işığı Yansıma değerleri (b) (ASTM C1519) ve Isı Yayılım (e) (ASTM C1371) değerlerinin ölçülmesi gerekir.Güneş ışığı yansıtma ve ısıl yayılım ölçüm değerlerinin Eşitlik 1-3'de yerine konmasıyla o 
numunenin SRI değeri hesaplanabilmektedir (ASTM E1980-11).

$$
\begin{aligned}
& \alpha=1-\beta \\
& X=\left(\frac{\alpha-0.029 \varepsilon)(8.797+h)}{9.5205 \varepsilon+h)}\right) \\
& S R I=123.97-141.35 x+9.655 x^{2}
\end{aligned}
$$

ASTM E1980-11 standardında önerilen düşük, orta ve yüksek rüzgar koşulları göz önünde bulundurularak taşınım katsayısı (h) değeri 5, 12 ve $30 \mathrm{Wm}-2 \mathrm{~K}-1$ olarak ayrı ayrı dikkate alınarak her bir h durumu için tüm koşullarda ölçümleri yapılan numunelerin SRI değerleri hesaplanmaktadır.

\section{DENEYSEL ÇALIŞMALAR}

\section{1. Çalışmada Kullanılan Doğal Taşlar}

Çalışma kapsamında, gerek yurt içi ve gerekse yurt dışında yüksek ticari öneme sahip farklı renk, doku ve yüzey (cilalı, honlu ve kumlamalı) özelliklerine sahip 5 farklı karbonat kökenli doğal taş türüne ait numuneler kullanılmıştır (Çizelge 1). Ayrıca, $15 \times 15 \times 2 \mathrm{~cm}$ boyutuna getirilmiş olan doğal taş plakalarının yüzeyleri üzerinde Güneş Işığı Yansıma değerleri (b) ve Isıl Yayılım (e) değerlerinin ölçümü için gerekli $5 \mathrm{~cm}$ kenar uzunluğunda 9 adet karelaj oluşturulmuştur

\begin{tabular}{|c|c|c|c|c|}
\hline $\begin{array}{l}\text { Num. } \\
\text { Kodu }\end{array}$ & Köken & $\begin{array}{l}\text { Kayaç } \\
\text { Türü }\end{array}$ & Renk & Doku \\
\hline M1 & Sed. & Traverten & $\begin{array}{c}\text { Orta } \\
\text { Kahverengi }\end{array}$ & Mikrokristalin \\
\hline M2 & Sed. & Killi-Kireçtaşı & $\begin{array}{c}\text { Sarımsı } \\
\text { Gri }\end{array}$ & Sparitik \\
\hline M3 & Sed. & Kireçtaşı & $\begin{array}{c}\text { Sarımsı } \\
\text { Gri }\end{array}$ & Mikritik \\
\hline M4 & Sed. & Dolomit & $\begin{array}{c}\text { ÇokAçık } \\
\text { Gri }\end{array}$ & Sparitik \\
\hline M5 & Met. & Mermer & $\begin{array}{l}\text { Beyaz- } \\
\text { AçıkGri }\end{array}$ & Granoblastik \\
\hline
\end{tabular}
(Foto 1-2).

Çizelge 1. Çalışmada kullanılan doğal taşlar

Sed: Sedimanter; Met: Metamorfik

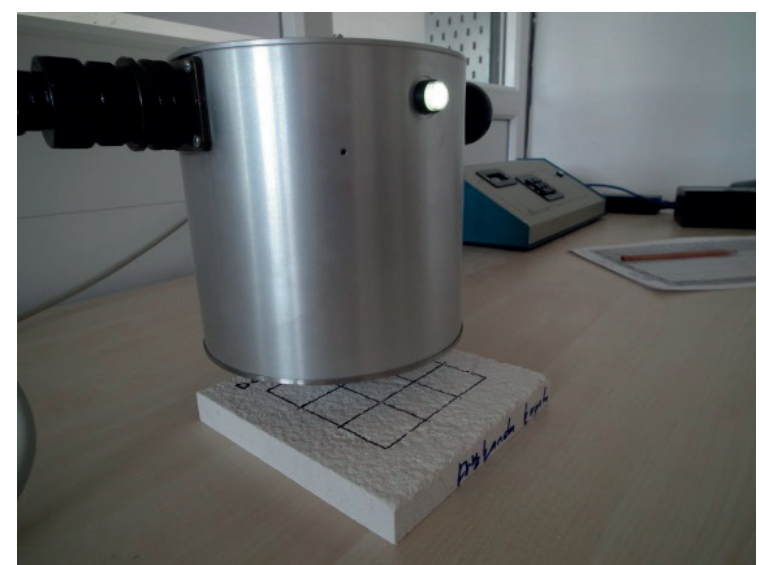

Foto 1. Güneş ışığı yansıma değeri ölçümü

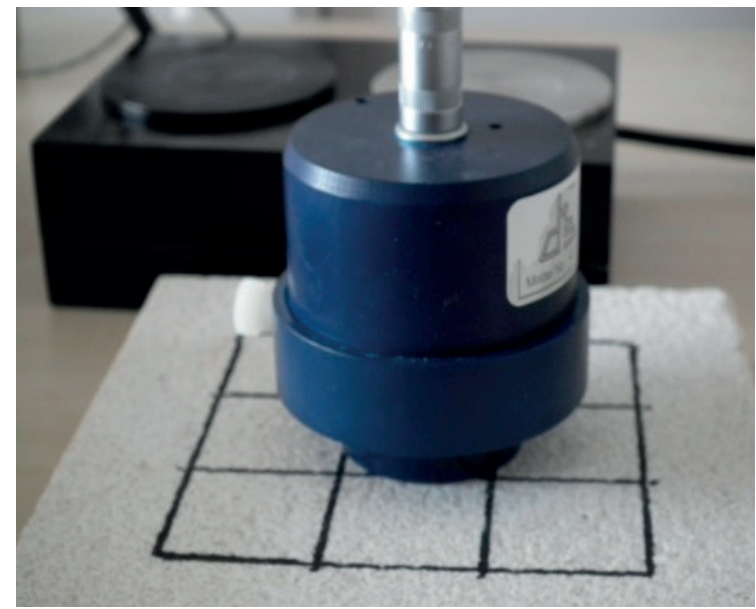

Foto 2. Isıl yayılım değeri ölçümü

\subsection{SRI Değerlerinin Belirlenmesi}

Numunelerin Güneş Işığını Yansıtma İndeks (Solar Reflection Index, SRI) değerlerinin belirlenmesi amacıyla Güneş Işığı Yansıma değerleri (b) ve Isıl Yayılım (e) değerleri Şekil 1-2'de verilen cihazlar kullanılarak ölçülmüş ve sonuçlar Çizelge 2'de sunulmuştur. Çalışma kapsamında numunelerin kuru ve suya doygun durumda ölçümleri yapılmıştır. Güneş Işığını Yansıtma İndeks (SRI) değerleri Eşitlik 1-3 kullanılarak hesaplanmış ve sonuçlar Çizelge 3'de verilmiştir. 
Çizelge 2. Çalışmada kullanılan doğal taşların ölçülen Güneş Işığı Yansıma ve Isıl Yayılım değerleri

\begin{tabular}{|c|c|c|c|c|c|c|c|}
\hline \multirow{3}{*}{$\begin{array}{l}\text { Num. } \\
\text { Kodu }\end{array}$} & \multirow{3}{*}{ Koşul } & \multicolumn{3}{|c|}{ Güneş Işı̆̆ı Yansıma değerleri $(\beta)$} & \multirow{2}{*}{\multicolumn{3}{|c|}{$\begin{array}{l}\text { Isıl Yayılım }(\varepsilon) \\
(\text { ASTM C1371) }\end{array}$}} \\
\hline & & & (ASTM C1549) & & & & \\
\hline & & Cilalı & Honlu & Kumlu & Cilalı & Honlu & Kumlu \\
\hline M1 & & $0.860 \pm 0.003$ & $0.875 \pm 0.005$ & $0.882 \pm 0.007$ & $0.502 \pm 0.076$ & $0.578 \pm 0.050$ & $0.658 \pm 0.049$ \\
\hline M2 & & $0.843 \pm 0.004$ & $0.846 \pm 0.004$ & $0.862 \pm 0.002$ & $0.907 \pm 0.005$ & $0.905 \pm 0.003$ & $0.911 \pm 0.003$ \\
\hline M3 & Kuru & $0.834 \pm 0.005$ & $0.851 \pm 0.002$ & $0.870 \pm 0.001$ & $0.770 \pm 0.024$ & $0.811 \pm 0.038$ & $0.855 \pm 0.015$ \\
\hline M4 & & $0.848 \pm 0.002$ & $0.861 \pm 0.001$ & $0.871 \pm 0.003$ & $0.684 \pm 0.052$ & $0.691 \pm 0.036$ & $0.770 \pm 0.026$ \\
\hline M5 & & $0.851 \pm 0.002$ & $0.860 \pm 0.001$ & $0.878 \pm 0.003$ & $0.469 \pm 0.024$ & $0.505 \pm 0.049$ & $0.664 \pm 0.031$ \\
\hline M1 & & $0.900 \pm 0.003$ & $0.908 \pm 0.005$ & $0.947 \pm 0.004$ & $0.389 \pm 0.052$ & $0.443 \pm 0.054$ & $0.404 \pm 0.056$ \\
\hline M2 & & $0.913 \pm 0.004$ & $0.922 \pm 0.002$ & $0.954 \pm 0.004$ & $0.711 \pm 0.004$ & $0.702 \pm 0.005$ & $0.704 \pm 0.005$ \\
\hline M3 & Doygun & $0.934 \pm 0.005$ & $0.932 \pm 0.005$ & $0.974 \pm 0.003$ & $0.698 \pm 0.018$ & $0.718 \pm 0.018$ & $0.708 \pm 0.010$ \\
\hline M4 & & $0.897 \pm 0.006$ & $0.927 \pm 0.005$ & $0.964 \pm 0.007$ & $0.490 \pm 0.044$ & $0.496 \pm 0.030$ & $0.553 \pm 0.022$ \\
\hline M5 & & $0.880 \pm 0.001$ & $0.896 \pm 0.005$ & $0.940 \pm 0.004$ & $0.384 \pm 0.013$ & $0.402 \pm 0.022$ & $0.453 \pm 0.026$ \\
\hline
\end{tabular}

Çizelge 3. Çalışmada kullanılan doğal taşların hesaplanan SRI değerleri

\begin{tabular}{|c|c|c|c|c|c|c|c|}
\hline \multirow{3}{*}{$\begin{array}{l}\text { Num. } \\
\text { Kodu }\end{array}$} & \multirow{3}{*}{$\begin{array}{l}\text { Yüzey } \\
\text { Koşulu }\end{array}$} & \multicolumn{6}{|c|}{ Güneş Işığını Yansıtma İndeks (SRI) Değeri } \\
\hline & & \multicolumn{3}{|c|}{$\begin{array}{l}\text { Taşınım katsayısı (h) } \\
\text { (Kuru Durum) }\end{array}$} & \multicolumn{3}{|c|}{$\begin{array}{l}\text { Taşınım katsayısı (h) } \\
\text { (Doygun Durum) }\end{array}$} \\
\hline & & $5 \mathrm{Wm}^{-2} \mathrm{~K}^{-1}$ & $12 \mathrm{Wm}^{-2} \mathrm{~K}^{-1}$ & $30 \mathrm{Wm}^{-2} \mathrm{~K}^{-1}$ & $5 \mathrm{Wm}^{-2} \mathrm{~K}^{-1}$ & $12 \mathrm{Wm}^{-2} \mathrm{~K}^{-1}$ & $30 \mathrm{Wm}^{-2} \mathrm{~K}^{-1}$ \\
\hline M1 & & 56.4 & 57.4 & 58.3 & 43.3 & 43.8 & 44.2 \\
\hline M2 & & 113.7 & 113.9 & 114.1 & 87.3 & 87.4 & 87.5 \\
\hline M3 & Cilalı & 93.5 & 94.1 & 94.7 & 86.0 & 86.0 & 85.9 \\
\hline M4 & & 81.5 & 82.2 & 82.9 & 56.7 & 57.1 & 57.5 \\
\hline M5 & & 51.4 & 52.6 & 53.7 & 41.5 & 42.3 & 43.1 \\
\hline M1 & & 67.5 & 68.2 & 68.7 & 50.9 & 51.2 & 51.4 \\
\hline M2 & & 113.5 & 113.7 & 113.9 & 86.3 & 86.3 & 86.3 \\
\hline M3 & Honlu & 99.9 & 100.3 & 100.6 & 88.8 & 88.7 & 88.7 \\
\hline M4 & & 82.8 & 83.5 & 84.0 & 58.9 & 58.9 & 58.8 \\
\hline M5 & & 56.7 & 57.7 & 58.6 & 44.8 & 45.3 & 45.8 \\
\hline M1 & & 79.0 & 79.4 & 79.8 & 47.9 & 47.6 & 47.2 \\
\hline M2 & & 114.6 & 114.7 & 114.9 & 87.5 & 87.3 & 87.0 \\
\hline M3 & Kumlu & 106.5 & 106.8 & 107.0 & 88.6 & 88.2 & 87.8 \\
\hline M4 & & 94.4 & 94.7 & 95.1 & 67.9 & 67.4 & 66.9 \\
\hline M5 & & 79.6 & 80.1 & 80.5 & 53.8 & 53.6 & 53.4 \\
\hline
\end{tabular}




\section{BULGULAR VE TARTIŞMALAR}

Karbonat kökenli 5 farklı (M1, M2, M3, M4, M5) doğal taş türüne ait, cilalı, honlu ve kumlu yüzeyler üzerinde, numunelerin kuru ve suya doygun olma durumlarına göre yapılan Güneş Işığı Yansıma (b) ve Isıl Yayılım (e) ölçümleri (Çizelge 2) sonucunda hesaplanan SRI değerleri (Çizelge 3) incelendiğinde, baz alınan sabit taşınım katsayısına ( $h=5)$ göre, M2 kodlu doğal taş örneğinin su içeriği ve yüzey pürüzlülüğünden neredeyse hiç etkilenmediği (Şekil 4) görülmektedir. Bunun nedeni zaten oldukça yüksek seviyede bir SRI değerine sahip olan kayacın bu parametrelerden etkilenme yüzdesinin daha düşük seviyede kalmasıdır. Buna karşın M1, M3, M4 ve M5 kodlu örneklerde pürüzlülük derecesi arttıkça SRI değerlerinde önemli ölçüde bir artış gözlenmiş, kuru ve kumlu yüzeylerde en yüksek SRI değerlerinin elde edilmiştir (Şekil 1-5). SRI değerlerinde görülen artışın, özellikle kuru durumda, doğal taş yüzeylerinde artan pürüzlülükle birlikte meydana gelen daha açık tondaki renksel değişimlerden kaynaklandığı düşünülmektedir.

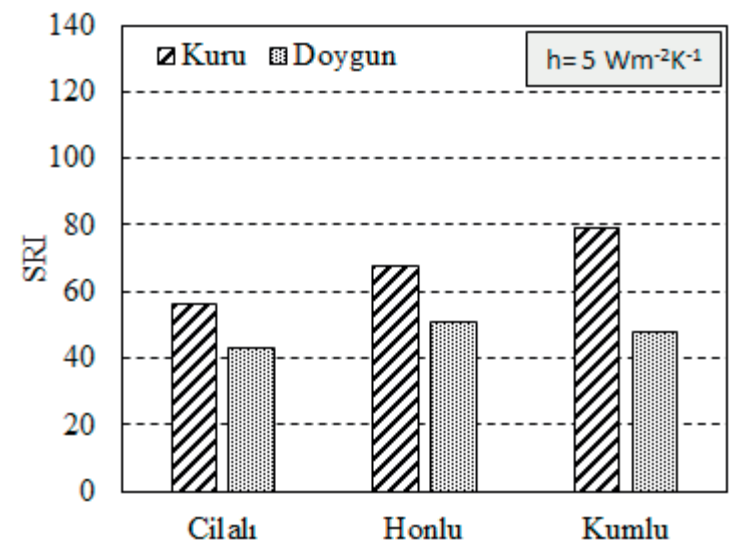

Şekil 1. M1 kodlu doğal taşa ait SRI sonuçları

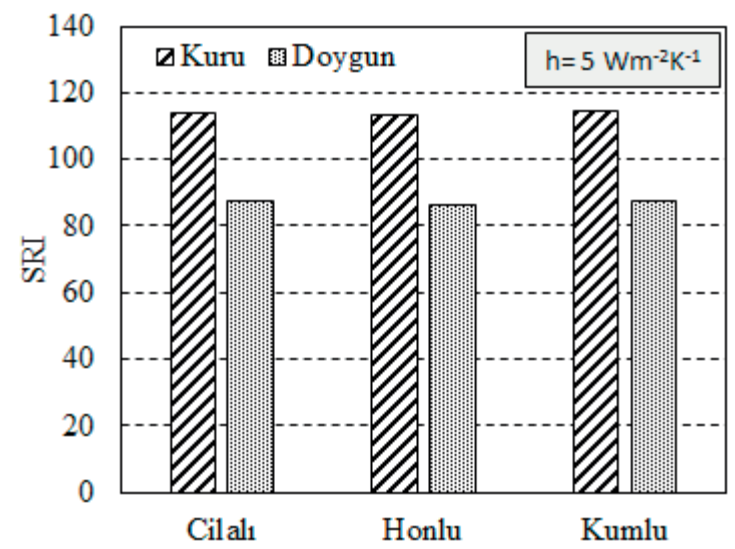

Şekil 2. M2 kodlu doğal taşa ait SRI sonuçları

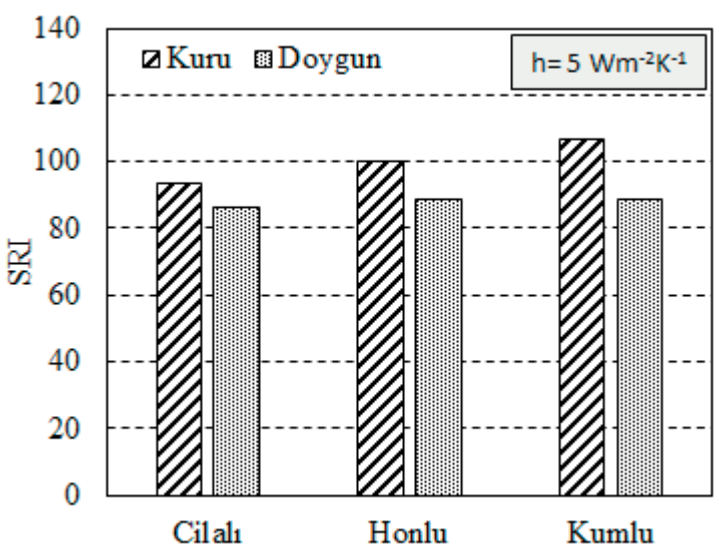

Şekil 3. M3 kodlu doğal taşa ait SRI sonuçları

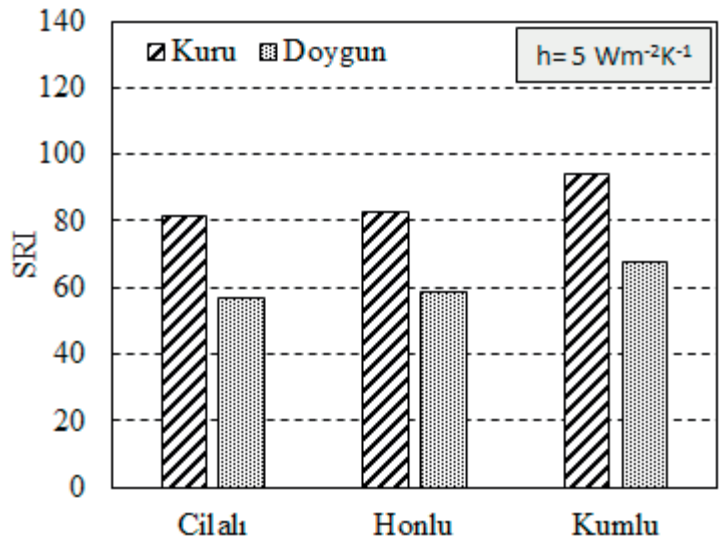

Şekil 4. M4 kodlu doğal taşa ait SRI sonuçları

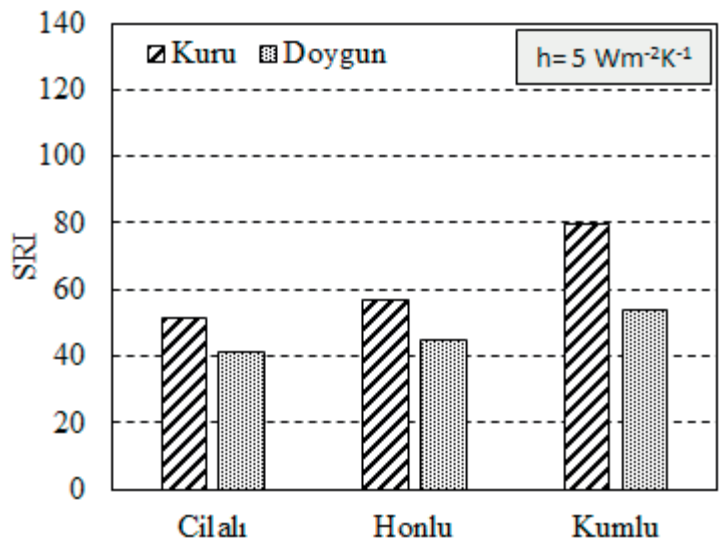

Şekil 5. M5 kodlu doğal taşa ait SRI sonuçları

\section{SONUÇLAR VE ÖNERILER}

Yukarıda elde edilen bulgular ışığında, çalışmada kullanılan tüm doğal taş türleri, farklı su içeriğinde ve yüzey koşullarında hesaplanan SRI değerleri açısından incelendiğinde, güneşten yayılan 
enerjiyi belirli ölçüde yansıtma kabiliyetine sahip oldukları ve özellikle M2 kodlu doğal taş türü için diğerlerine nazaran daha serin bir yüzeye sahip olabileceği sonucuna varılmıştır. Diğer doğal taş türleri için ise genellikle kaba işlenmiş ve kuru yüzeyler tercih edildiğinde oldukça tatmin edici sonuçlar doğuracağı, artan SRI değerlerinin ise, doğal taş kullanımında çok büyük yüzey alanları söz konusu olduğunda, bulundukları ortamlarda oluşabilecek ısı adalarının azalmasına da önemli derecede katkı sağlayabilecekleri sonucuna ulaşıımıştır.

Ayrıca yeşil bina değerlendirme sistemi ve çevresel sürdürülebilir yapı için uygun standartları oluşturmak üzere, ABD Yeşil Bina Konseyi (U.S. Green Building Council, 2007) tarafından geliştirilen "Enerji ve Çevre Tasarımında Öncülük" (The Leadership in Energy and Environmental Design, LEED) sertifikasyonu kapsamında, binalarda kaplama olarak kullanılacak doğal taşların SRI değerinin 29'un üzerinde olması gerektiği önerilmektedir. Bu çalışmada incelenen 5 farklı doğal taş için hesaplanan SRI değerlerinin, 29'un üzerinde olduğu ve bu öneriyi sağladıkları belirlenmiştir.

\section{TEŞEKKÜR}

Bu çalışma, TÜBITTAK-1001 "Bilimsel ve Teknolojik Araştırma Projelerini Destekleme Programı" kapsamında 114M569 No'lu Proje tarafından desteklenmiştir. Kuruma katkıları için teşekkür ederiz.

\section{KAYNAKLAR}

Alchapar, N.L.,Correa, E.N., Canton, M.A., (2013), Solar Reflectance Index of Pedestrian Pavements and Their Response to Aging, Journal of Clean Energy Technologies, 1 (4), 281-285.

ASTM C1371, (2015), American Society For Testing and Materials, Standard Test Method for Determination of Emittance of Materials Near Room Temperature Using Portable Emissometers. ASTM C1549, (2009), American Society For
Testing and Materials, Standard Test Method for Determination of Solar Reflectance Near Ambient Temperature Using a Portable Solar Reflectometer.

ASTM E1980 - 11 (2001), American Society for Testing and Materials, Standard Practice for Calculating Solar Reflectance Index of Horizontal and Low-Sloped Opaque Surfaces.

Berdahl P.,Bretz S.E., (1997), Preliminary Survey of The Solar Reflectance of Cool Roofing Materials, Energy and Buildings, 25, 149-158.

Boriboonsomsin K.,Reza F., (2007), Mix Design And Benefit Evaluation of High Solar Reflectance Concrete For Pavements, Transportation Research Board of the National Academies, 1120.

Kültür, S. Türkeri, N.,(2012), Assessment of Longterm Solar Reflectance Performance of Roof Coverings Measured In Laboratory and In Field, Building and Environment, 48, 164-172.

Levinson, R.,Akbari, H., Berdahl, P.,(2010), Measuring Solar reflectance-Part II: Review of Practical Methods, Solar Energy, 84, 1745-1759.

Ma, Y.,Zhu, B., Wu, K., (2001), Preparation ünd Solar Reflectance Spectra of Chameleon Type Building Coatings, Solar Energy, 70 (5), 417-422.

Shi Z, Zhang X., (2011), Analyzing the Effect of the Long Wave Emissivity and Solar Reflectance of Building Envelopes on Energy-Saving In Buildings In Various Climates, Solar Energy, 85:28-37.

Sleiman, M.,Kirchstettera, T.W., Berdahl, P., Gilbert, H.E., Quelen, S., Marlot, L., Preblea, C.V., Chen, S., Montalbano, A., Rosseler, O., Akbari, H., Levinson, R., Destaillats, H., (2011), Soiling of Building Envelope Surfaces ünd Its Effect on Solar Reflectance - Part li: Development of an Accelerated Aging Method for Roofing Materials, Solar Energy Materials and Solar Cells, 122, 271281.

U.S.Green Building Council, (2007), 5 September 2007, www.usgbc.org. 